\title{
Click-evoked vestibular activation in the Tullio phenomenon
}

\author{
J G Colebatch, J C Rothwell, A Bronstein, H Ludman
}

\begin{abstract}
Click-evoked vestibulocollic reflexes were studied in a patient with a unilateral Tullio phenomenon (sound induced vestibular symptoms) and the findings were compared with those of a group of normal subjects. Compared with normal subjects, the reflexes elicited from her symptomatic side were large and had an abnormally low threshold, but retained a normal waveform. The click-evoked responses in this patient show changes consistent with her symptomatology and are indicative of a pathological increase in the normal vestibular sensitivity to sound.
\end{abstract}

$(\Im$ Neurol Neurosurg Psychiatry 1994;57:1538-1540)

Patients with the Tullio phenomenon experience vestibular symptoms when they hear specific, usually loud, sounds. Reported precipitants include rumbling noises of traffic and trucks, noises of a crowded bazaar, ${ }^{1}$ campanology (bell ringing) ${ }^{2}$ car horns, ${ }^{3}$ and saying certain vowels. ${ }^{4}$ Clinically it is possible to induce nystagmus in these patients with sound, which, although loud, has no such effect in control subjects.

Very loud sounds (over $130 \mathrm{~dB}$ SPL) can cause vestibular symptoms in normal subjects, ${ }^{6-8}$ but usually these intensities are only achieved near jet engines or explosives. It is thought that, under these conditions, the sound pressure wave set up in the inner ear can directly activate vestibular receptors. By making the sound duration very short (clicks), these high sound intensities can be presented safely. ${ }^{9}$ Colebatch et $a l^{10}$ showed that loud clicks evoked a short latency EMG response in the contracting sternocleidomastoid muscles and presented evidence that this represented a vestibulocollic reflex, possibly originating from saccular afferents. Given these findings, it is natural to speculate whether the Tullio phenomenon simply represents an exaggeration of the normal condition (a lower threshold than normal for acoustic activation of the vestibular apparatus) or whether there might also be a more fundamental alteration in the nature of the vestibular activity induced by sound in these patients. We have recently had the opportunity of applying this new technique in a patient with an established Tullio phenomenon to consider this issue.

\section{Subjects and methods}

CASE HISTORY

The patient, a 55 year old woman, reported that she had experienced left retroauricular pain and impaired balance after a series of forceful sneezes six years previously. Pressure over the mastoid area or loud sounds made her feel unsteady and veer to the left, and also made her retroauricular pain worse. Associated with these symptoms was the illusion of objects "swimming" in front of her. Clinical examination of her eye movements as well as the remainder of the neurological examination were normal. The Hallpike manoeuvre was negative bilaterally. Loud tones $(1 \mathrm{kHz}, 110 \mathrm{~dB}$ ISO) presented to the left ear through earphones caused visible nystagmus. This consisted mainly of conjugate torsional left beating and down beating components. ${ }^{11}$ Similar loud sounds presented to the right ear did not cause nystagmus. Pure tone audiograms, stapedial reflex thresholds, bithermal caloric tests, CT of the temporal bone, and cranial MRI were normal. The middle ear was normal when surgically explored (HL).

Click stimuli were delivered through earphones with the patient sitting. ${ }^{10}$ Surface EMG recordings were made over the right and left sternocleidomastoid muscles with a reference electrode over the sternoclavicular joint and the active electrode over the muscle belly (interelectrode distance $6-8 \mathrm{~cm}$ ). Clicks $0.1 \mathrm{~ms}$ long were applied at $3 / \mathrm{s}$ pseudorandomly to either the right or left ear. The click generator was purpose built and calibrated to produce clicks from $70 \mathrm{~dB}$ to $100 \mathrm{~dB}$ above normal hearing threshold $(0 \mathrm{~dB} \mathrm{NHL}=45$ $\mathrm{dB}$ SPL for $0.1 \mathrm{~ms}$ click). In this report, sound intensities are measured with respect to (normal) hearing threshold as this is the common method by which commercial click generators are calibrated. It is important to note that impulse noise intensity is formally defined in $\mathrm{dB}^{\mathrm{SPL}}{ }^{9}$ and this physical rather than perceptual intensity is the more relevant to the effects on the vestibular apparatus.

The patient was instructed to activate her neck flexors tonically. Averages of both unrectified and rectified EMG were made $(n=256)$ with a laboratory interface and associated commercial software (SIGAVG Ver 6.0, Cambridge Electronic Devices, Cambridge, UK). The patient's results were compared with those of 25 normal volunteers (ages 22 to 65 ) tested under similar conditions but with a commercial click generator 
Recordings made from over the patient's right sternocleidomastoid $(A)$ and left

sternocleidomastoid muscle (B). In each case, the averaged effects of stimulating the ipsilateral ear are shown. The effects of unilateral clicks of three different intensities are illustrated. Click intensities are given relative to the reference intensity $(45 \mathrm{~dB}$ SPL: see text). All averages were made of the effects of 256 presentations of the click stimulus which was given 20 ms after the traces began, at

time $=0$. Positive potentials at the active electrode caused a downward deflection. When the symptomatic (left) ear was stimulated, a clear p13-n23 response was visible with lowest intensity used (70 dB), a lower level than for any of the normal subjects tested. By contrast, the p13-n23 response on the right side was only first seen with $90 \mathrm{~dB}$ clicks.

A

\section{Right ear}

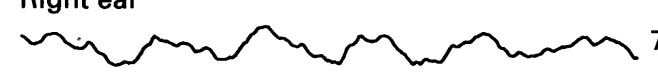

$70 \mathrm{~dB}$
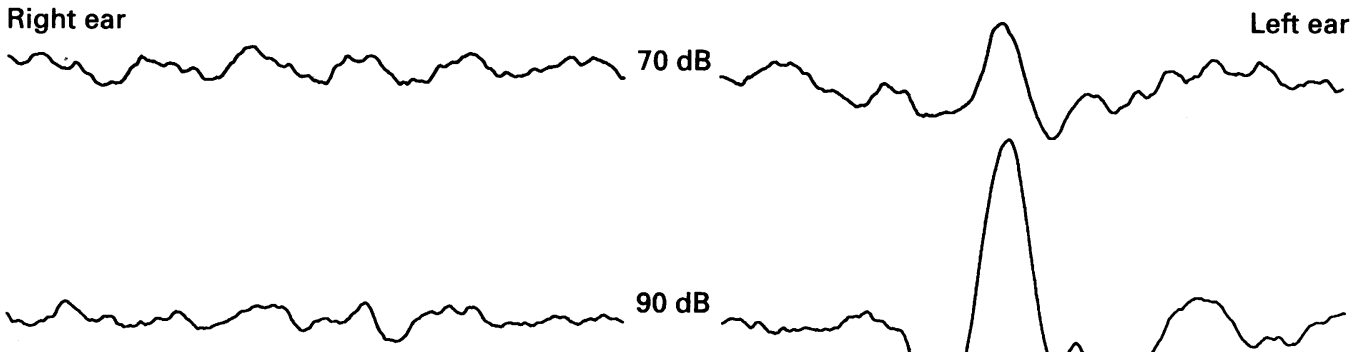

$90 \mathrm{~dB}$

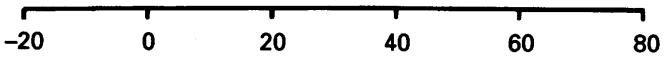

Time (ms)
Click induced vestibulocollic reflexes in left Tullio phenomenon

\begin{tabular}{|c|c|c|c|c|c|c|}
\hline \multirow[b]{2}{*}{$\begin{array}{l}\text { Intensity } \\
(d B N H L)\end{array}$} & \multicolumn{3}{|l|}{ Right } & \multicolumn{3}{|l|}{ Left } \\
\hline & $p 13 / n 23$ & $\begin{array}{l}\text { Rect EMG } \\
(\mu V)\end{array}$ & Ratio & $p 13-n 23$ & $\begin{array}{l}\text { Rect EMG } \\
(\mu V)\end{array}$ & Ratio \\
\hline $\begin{array}{r}70 \\
80 \\
90 \\
95 \\
100\end{array}$ & $\begin{array}{l}\overline{ } \\
\overline{12} \cdot 7 \\
24 \cdot 9 \\
37 \cdot 9\end{array}$ & $\begin{array}{l}\overline{ } \\
\overline{72} \cdot 2 \\
81 \cdot 1 \\
82 \cdot 6\end{array}$ & $\begin{array}{l}\overline{-} \\
\overline{0.18} \\
0.31 \\
0.46\end{array}$ & $\begin{array}{r}51.2 \\
79.7 \\
152.2 \\
191.7 \\
191.3\end{array}$ & $\begin{array}{l}68 \cdot 9 \\
59 \cdot 8 \\
69 \cdot 4 \\
88 \cdot 5 \\
80 \cdot 7\end{array}$ & $\begin{array}{l}0 \cdot 74 \\
1 \cdot 33 \\
2 \cdot 19 \\
2 \cdot 17 \\
2 \cdot 37\end{array}$ \\
\hline
\end{tabular}

The intensity of the clicks $(0.1 \mathrm{~ms}$ duration) is given in the left column where $0 \mathrm{~dB}$ NHL $=45$ dB SPL. The three columns thereafter detail the vestibulocollic reflexes recorded from the right sternocleidomastoid muscle in response to clicks given to the right ear. The last three columns give the same results for clicks given to the left ear, using recordings made over the left sternocleidomastoid. The peak to peak amplitude of the p13-n23 response ${ }^{10}$ is given first, then the mean rectified EMG, and finally the size of the response as a ratio of the background EMG activity. The threshold and amplitudes on the right side were within the range of the normal controls. On the left, the response began at a lower threshold than normal and was correspondingly larger. Correction for background activity indicated that the size of the response on the left became saturated at $90 \mathrm{~dB}$. sity stimulus (70 dB) and increased in amplitude and saturated with $90 \mathrm{~dB}$ clicks. Peaks consistent with $\mathrm{n} 35$ and $\mathrm{p} 44^{10}$ were present after the more intense stimuli. The p13-n23 response on the right side began with $90 \mathrm{~dB}$ clicks and increased in size with louder clicks but was always much smaller than on the left. The latency of the initial positivity was slightly longer on the left than on the right $(16.6 v 12.2 \mathrm{~ms})$. There was no sensation of vertigo or visible eye or head movement during click testing.

All the normal volunteers had p13-n23 responses when given stimuli at $100 \mathrm{~dB}$ but none had responses at $70 \mathrm{~dB}$ (mean threshold: right $87 \mathrm{~dB}$, left $86 \mathrm{~dB}$ ). The two normal subjects with the lowest thresholds had small responses to $75 \mathrm{~dB}$ clicks, with corrected amplitudes smaller $(0.35-0.51)$ than those seen in the patient with $70 \mathrm{~dB}$ clicks. The size of the patient's left sided response, corrected for background activity, was also larger than that in any control subject at an intensity of $80 \mathrm{~dB}$. At intensities of $90 \mathrm{~dB}$ and higher, p13-n23 responses similar in amplitude to those of the patient were sometimes found in normal subjects: thus for $100 \mathrm{~dB}$ clicks, corrected amplitudes over 2.37 (the maximum size of the patient's response) were recorded from three normal volunteers (four ears). The threshold difference between the ears for eliciting the p13-n23 response was never greater than $10 \mathrm{~dB}$ in the normal volunteers.

\section{Discussion}

Colebatch et al ${ }^{10}$ presented evidence, based on changes seen in patients with selective 8 th nerve lesions, that the initial positive-negative 
potential ( $\mathrm{p} 13-\mathrm{n} 23)$ seen in recordings from over the sternocleidomastoid muscle after loud clicks to the ipsilateral ear was the result of vestibular activation. Consistent with such a conclusion, we found that our patient with the Tullio phenomenon had a pathologically low threshold for this response when sound was applied to the symptomatic ear. Our estimate for the threshold for click activation of the vestibular apparatus in this ear, of the order of $110 \mathrm{~dB}$ SPL, is at least $5-10 \mathrm{~dB}$ lower than that in the most sensitive normal subjects and is consistent with the sound level required to induce nystagmus $(110 \mathrm{~dB}$ ISO $\simeq 117 \mathrm{~dB}$ SPL at $1 \mathrm{kHz}) .{ }^{12}$ Her threshold for click activation of the vestibular apparatus on the right was normal, so it is likely that the process that resulted in her developing the Tullio phenomenon had the net effect of increasing her vestibular sensitivity to sound by over $20 \mathrm{~dB}$ (more than a 10-fold increase in sensitivity). The process by which this occurred is uncertain, but seemed not to be the result of dislocation of the stapes (compare Dieterich et al $^{3}$ ).

At the higher intensities, the click induced vestibulocollic reflex on the left increased in amplitude and became saturated. Even with stimuli more than $30 \mathrm{~dB}$ above the patient's threshold - a relative intensity not achievable in normal subjects-the form of the evoked response remained the same as for normal subjects: indeed, the reflexes evoked by 100 $\mathrm{dB}$ clicks were indistinguishable from those occurring in some normal subjects after the same stimuli. Thus no evidence was found to suggest a fundamental change in vestibular response to sound in addition to its increased sensitivity.

Click activation of the vestibular apparatus can indicate pathologically increased sensitivity to sound in cases of the Tullio phenomenon.

This work is supported by the National Health and Medica Research Council of Australia. A Wellcome-Ramaciotti Travel grant allowed JCC to be present while the patient was studied. We thank the patient for her cooperation. Mr R Bedlington kindly designed and made the click generator used in the experiments on the patient.

1 Kacker SK, Hinchcliffe R. Unusual Tullio phenomena. F Laryngol Otol 1970;84:155-66.

Stephens SDG, Ballam HM. The sono-ocular test. f Laryngol Otol 1974;88:1049-59.

Dieterich $M$, Brandt Th, Fries W. Otolith function in man. Brain 1989;112:1377-92.

4 Deeke L, Mergner T, Plester D. Tullio phenomenon with torsion of the eyes and subjective tilt of the visual surround. Ann New York Acad Sci 1981;374:650-5.

5 Vogel P, Tackmann W, Schmidt F-J. Observations on the Tullio phenomenon. $\mathcal{F}$ Neurol 1986;233:136-9.

6 von Békésy G. Uber akustische Reizung des Vestibularapparates. Pflügers Arch 1935;236:59-76.

7 Dickson EDD, Chadwick DL. Observations on disturbances of equilibrium and other symptoms induced by bances of equilibrium and other symptoms indu

8 Erlich MA, Lawson $\mathrm{W}$. The incidence and significance of the Tullio phenomenon in man. Otolaryngol Head Neck Surg 1980;88:630-5.

9 Atherley GRC, Martin AM. Equivalent-continuous noise level as a measure of injury from impact and impulse noise. Ann Occup Hyg 1971;14:11-28.

10 Colebatch JG, Halmagyi GM, Skuse NF. Myogenic potentials generated by a click-evoked vestibulocollic reflex. F Neurol Neurosurg Psychiatry 1994;57:190-7.

11 Bronstein AM, Faldon M, Rothwell J, Gresty MA, Colebatch J, Ludman H. Clinical and electrophysiological findings in Tullio phenomenon. Acta Otolaryngol (Stockh) 1994 (in press).

12 Martin MC. Audiometers. In: Beagley HA, ed. Audiology and audiological medicine. Oxford: Oxford University Press, 1981:161-85. 